\title{
Unmasking of the trigemino-accessory reflex in accessory facial anastomosis
}

\author{
Angel Esteban, Julio Prieto
}

\begin{abstract}
Objective-To evaluate the possible blink reflex responses in facial muscles reinnervated by the accessory nerve.

Method-Eleven patients with a complete facial palsy were submitted to a surgical repair by an accessory facial nerve anastomosis (AFA). In this pathological group, blink reflex was studied by means of percutaneous electrical stimulation of the supraorbital nerve and recording from the orbicularis oculi muscle. A control group comprised seven normal people and seven patients with a complete Bell's facial palsy; in this group, responses on the sternocleidomastoideus (SCM) muscles were studied after supraorbital nerve stimulation.
\end{abstract}

Results-All the patients with AFA showed a consistent degree of facial reinnervation. Ten out of the 11 patients with AFA showed reflex responses; in six, responses were configured by a double component pattern, resembling the $R 1$ and $R 2$ components of the blink reflex; three patients had an $\mathrm{R} 1$-like response and one patient showed a unique $R 2$ component. Mean values of latencies were $\mathbf{1 5 . 2}$ (SD 4.6) $\mathrm{ms}$ for the R1 and 85.3 (SD 9.6) ms for the R2. In the control group, eight out of 14 people had evidence of reflex responses in the SCM muscles; these were almost exclusively configured by a bilateral late component (mean latency 63.5 (SD15.9) $\mathrm{ms}$ ) and only one of the subjects showed an early response at $11 \mathrm{~ms}$.

Department of Clinical Neurophysiology,

Hospital General Universitario Gregorio Marañón, Cl Dr

Esquerdo 46, 28007

Madrid, Spain

A Esteban

Department of Morphological

Sciences and

Physiology,

Universidad Europea,

C/ Tajo s/n, Villaviciosa

de Odón, 28670

Madrid, Spain

J Prieto

Correspondence to: Dr A Esteban, Department of Clinical Neurophysiology, Hospital General Gregorio Marañón, C/ Dr Esquerdo 46, 28007 Madrid, Spain.

Received 27 July 1998 and in revised form

26 January 1999

Accepted 5 March 1999 the trigeminal and the accessory limbs of the reflex. The findings described could be a demonstration of neurobionomic function in the repairing process of the nervous system.

(F Neurol Neurosurg Psychiatry 1999;67:379-383)

Keywords: blink reflex; trigemino-accessory reflex; accessory facial nerve anastomosis; neuroplasticity

The evaluation of the trigeminofacial reflexes is a common exploration in neurological clinical practice. Electrophysiologically, the blink reflex is often used to test the brainstem. The meth- odology to obtain this reflex and the evaluation of its parameters are well established. Other trigeminal reflexes using rather different motor pathways than the blink reflex are much less known and employed. This is the case for the trigeminoaccesory or trigeminocervical reflex, first described in animals ${ }^{1}$ and later in humans. ${ }^{2}$

Table 1 Pathological group; complete facial palsy with subsequent accessory-facial anastomosis. Clinical data

\begin{tabular}{llllrl}
\hline Patient & Sex & Side & $\begin{array}{c}\text { Age } \\
(y)\end{array}$ & Evolution* & $\begin{array}{l}\text { Degree of } \\
\text { reinnervationt }\end{array}$ \\
\hline 1 & F & R & 59 & 25 & 3 \\
2 & F & R & 53 & 103 & 4 \\
3 & F & R & 66 & 6 & 2 \\
4 & F & L & 23 & 8 & 3 \\
5 & F & L & 36 & 33 & 3 \\
6 & F & R & 42 & 16 & 3 \\
7 & F & R & 35 & 7 & 2 \\
8 & M & R & 57 & 24 & 2 \\
9 & M & L & 55 & 5 & 2 \\
10 & F & R & 39 & 42 & 3 \\
11 & F & L & 67 & 30 & 4 \\
\hline
\end{tabular}

*Time since the accessory-facial anastomosis (in months). †Arbitrary scale from $0=$ none to $4=$ maximal.

Table 2 Control group; seven normal subjects and seven patients with complete facial palsy. Clinical data and trigeminoaccessory reflex responses

\begin{tabular}{lllll}
\hline & & \multicolumn{4}{c}{ Reflex responses $^{*}$} \\
\cline { 4 - 5 } Subject & $\begin{array}{l}\text { Facial } \\
\text { palsy }\end{array}$ & $\begin{array}{l}\text { Age } \\
(y)\end{array}$ & $\begin{array}{l}\text { Right trigeminal } \\
\text { stimulation }\end{array}$ & $\begin{array}{l}\text { Left trigeminal } \\
\text { stimulation }\end{array}$ \\
\hline 1 & No & 54 & R2 i, c & R2 i, c \\
2 & No & 48 & R2 i, c & NE \\
3 & No & 35 & R2 i, c & R2 i, c \\
4 & No & 32 & No & NE \\
5 & No & 44 & R2 i, c & R2 i, c \\
6 & No & 42 & No & No \\
7 & No & 45 & No & No \\
8 & L & 71 & R2 i, c & R2 i, c \\
9 & L & 74 & NE & R1; R2 i, c \\
10 & L & 63 & No & No \\
11 & R & 46 & No & No \\
12 & R & 56 & R2 i, c & R2 i, c \\
13 & R & 62 & No & No \\
14 & R & 62 & R2 i, c & R2 i, c \\
\hline
\end{tabular}

$\star$ Recorded on the sternocleidomastoideus muscles. $\mathrm{i}=$ Ipsilateral; $\mathrm{c}=$ contralateral; $\mathrm{NE}=$ non-explored; $\mathrm{R}=$ right; $\mathrm{L}=$ left.

Table 3 Pathological group. Reflex responses obtained on the facial muscles of the accessory-facial anastomosis side 

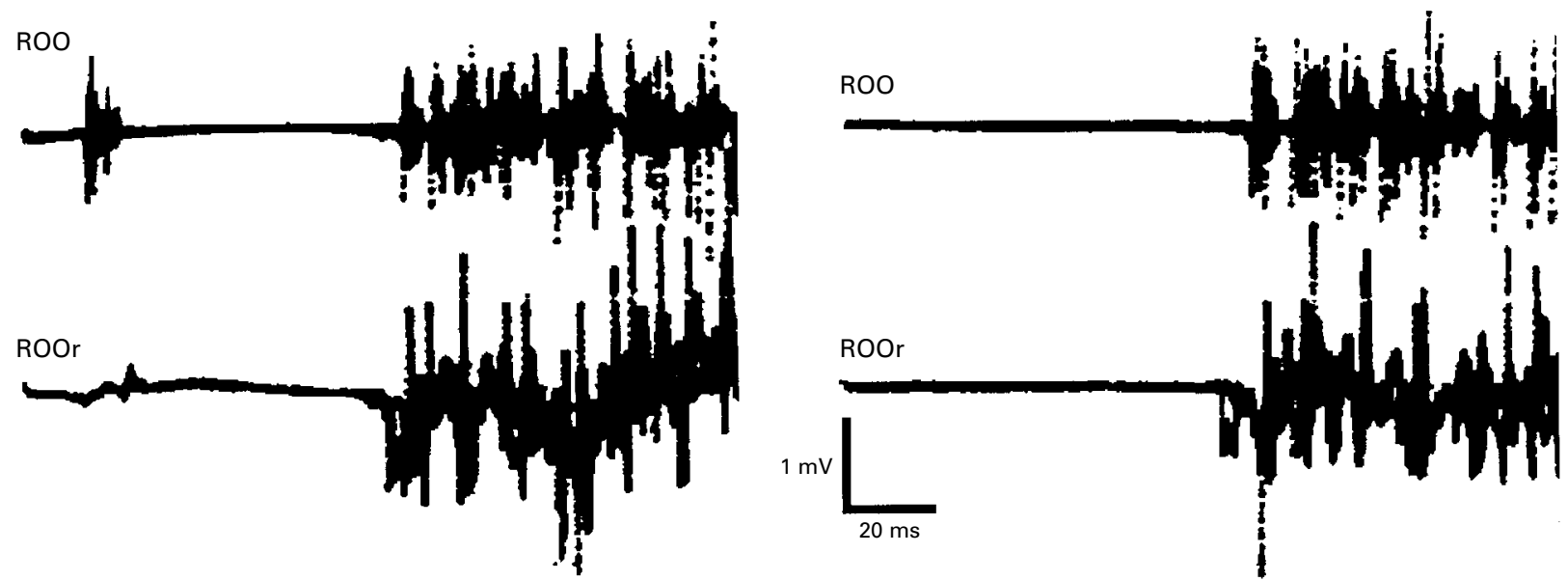

Figure 1 Patient 6. Right accessory-facial anastomosis. Simultaneous recording in right $(R)$ orbicularis oculi (OO) and orbicularis oris (OOr) muscles. $A$ double response ( $R 1$ and $R 2$ ) is obtained with the ipsilateral supraorbital nerve stimulation whereas the contralateral stimulation induces a single $R 2$ response in both muscles.

In clearly established lesions of the CNS, adaptative mechanisms and functional reorganisation phenomena can promote the development of substitutive motor activities in response to the requirements of the external environment. ${ }^{3}$

In this study, we have evaluated the presence of an unusual blink reflex in a group of patients with a complete anatomical lesion of the facial nerve in which the normal efferent pathway was surgically replaced by means of an accessory-facial anastomosis. The aim of the study was the evaluation of the incidence and configuration of the trigemino-accessory reflex in its normal cervical areas of expression as well as the variations that this reflex may present after the lesion and subsequent recovery of its peripheral motor limb.

\section{Patients and methods}

PATIENTS

Eleven patients (two men and nine women) formed the pathological group with a mean age

Right stimulation of 48.3 years (range 23 to 67 years) that had a complete facial palsy after surgery for acoustic neuroma (10 patients) or cholesteatoma (patient 9). All patients had undergone an accessory-facial anastomosis; the mean evolution time between surgery and the first electrophysiological evaluation was 27.2 (SD 28) months (range 5 to 103 months). The palsy side was right in seven and left in four patients (table 1).

Seven normal subjects (four women and three men) and seven patients with complete unilateral Bell's palsy (two women and five men) electrophysiologically confirmed formed the control group. Their mean age was 52.4 (SD 12.8) years (range 32 to 74 years, table 2).

\section{METHODS}

In the 11 patients with complete facial nerve palsy and accessory-facial anastomosis, we evaluated the degree of reinervation with an arbitrary scale from 0 to 4 for the EMG activity obtained in maximal contraction. The

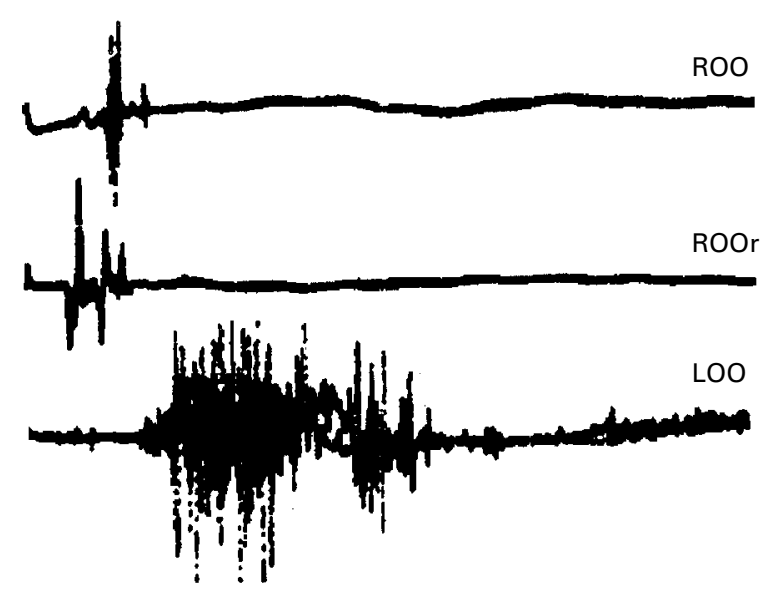

Left stimulation

Figure 2 Patient 2. Right accessory-facial anastomosis. A single early response (R1) is obtained in the orbicularis oculi (OO) and the orbicularis oris (OOr) muscles of the pathological side with the ipsilateral supraorbital nerve stimulation (right). No response is provoked with the left stimulation. Normal blink reflex responses in the left orbicularis oculi (LOO). 
Table 4 Values of trigeminoaccessory responses obtained within the pathological and control groups (mean (SD); in ms)

\begin{tabular}{llllll}
\hline \multirow{2}{*}{ Group } & \multirow{2}{*}{$\begin{array}{l}\text { No. } \\
\text { Sides }\end{array}$} & \multirow{2}{*}{$M^{*}$} & $R$ Reflex responses $t$ & $R$ \\
\cline { 4 - 6 } Pathological $\neq$ & 11 & $\begin{array}{l}6.4(3.2) \\
(\mathrm{n}=11)\end{array}$ & $\begin{array}{l}15.2(4.6) \\
(\mathrm{n}=8)\end{array}$ & $\begin{array}{l}85.3(9.6) \\
(\mathrm{n}=6)\end{array}$ & - \\
Controlฐ & 25 & - & $\begin{array}{l}11 \\
(\mathrm{n}=1)\end{array}$ & $\begin{array}{l}63.5(15.9) \\
(\mathrm{n}=14)\end{array}$ & $\begin{array}{l}74.1(16.6) \\
(\mathrm{n}=14)\end{array}$ \\
\hline
\end{tabular}

^Pretragal facial nerve stimulation.

tSupraorbitary nerve stimulation.

$\ddagger$ Recorded on facial muscles.

§Recorded on sternocleidomastoideus muscles.

$\mathrm{i}=$ Ipsilateral; $\mathrm{c}=$ contralateral. using Student's $t$ test. The incidence of the reflex response in these two subgroups was compared with a $\chi^{2}$ test, as was the incidence of the reflex response in the control group compared with those of the pathological group. The relation between the latency of MAP and the latency of R1 in the pathological group was tested with a linear regression.

\section{Results}

The degree of reinnervation obtained in the facial muscles after an accessory-facial anastomosis in the 11 patients of the pathological group is shown in table 1 . Two patients showed a maximal score, five an important degree of reinervation, and the other four a moderate one. The degree of reinnervation did not show a systematic correlation with the time of evolution. The stimulation of the supraorbital nerve ipsilateral to the lesion evoked a response in the facial muscles (innervated by the accesory nerve) in 10 out of the 11 patients (90.9\%), 16 sides of the 20 evaluated (table 3 ). Six patients $(1,4,5,6,7$, and 8$)$ showed a response formed by an early component (probably R1) and a late component resembling R2 (fig 1). In patients $1,2,6,9,10$, and 11 responses could also be obtained in other facial muscles different from $\mathrm{OO}$ ( $\mathrm{F}$ and OOr muscles) and in one patient (7) they were obtained only in the OOr muscle. In three patients $(2,10$, and 11$)$ the response contained only an early R1 component (fig 2) and in patient 9 only a late R2 component was present. The contralateral stimulation provoked $\mathrm{R} 2$ responses on the pathological side in six out of the nine patients evaluated (table 3 ). The mean value (SD) of latencies of the $\mathrm{R} 1$ and $\mathrm{R} 2$ responses recorded in the OO were $15.2(4.6) \mathrm{ms}$ and $85.3(9.6)$ $\mathrm{ms}$. The latency of direct response-which was obtained in all patients - showed a mean value of 6.4 (3.2) ms (table 4). A significant Pearson positive correlation $(R=0.924, \mathrm{p}<0.05)$ was shown between latency and the R1 reflex component latency (fig 3)

The homogeneity of the control group, formed by a subgroup of normal people and another subgroup of patients with complete facial palsy, was tested comparing the incidence of the responses with a $\chi^{2}$ test and the value of R2 latency obtained in each subgroup with the Student's $t$ test; there were no significant differences. In this group the incidence of reflex responses in the SCM muscles with supraorbital nerve stimulation was $57 \%$; they were obtained in eight out of 14 people, 14 sides of the 25 evaluated (table 2 ). Only patient 9 showed a double response formed by an early ipsilateral and a late bilateral component; seven patients showed only the bilateral late components (patients $1,2,3,5,8,12$, and 14 , fig 4 ), and in the other six patients $(4,6,7,10,11$, and 13) there was no response. The mean latency value of R2 ipsilateral to the stimulus was 63.5 (SD 15.9) $\mathrm{ms}(\mathrm{n}=14)$ and $74.1(\mathrm{SD} \mathrm{16.6)} \mathrm{ms}$ $(n=14)$ for the contralateral side (table 4$)$.

The difference in incidence of the reflex response between the pathological and the control groups was significant $(\mathrm{p}<0.05)$.
Figure 3 Linear correlation between $M$ potential latency and early reflex component $(R 1)$ in patients with accessory-facial anastomosis $(R=0.924 ; p<0.05)$. 


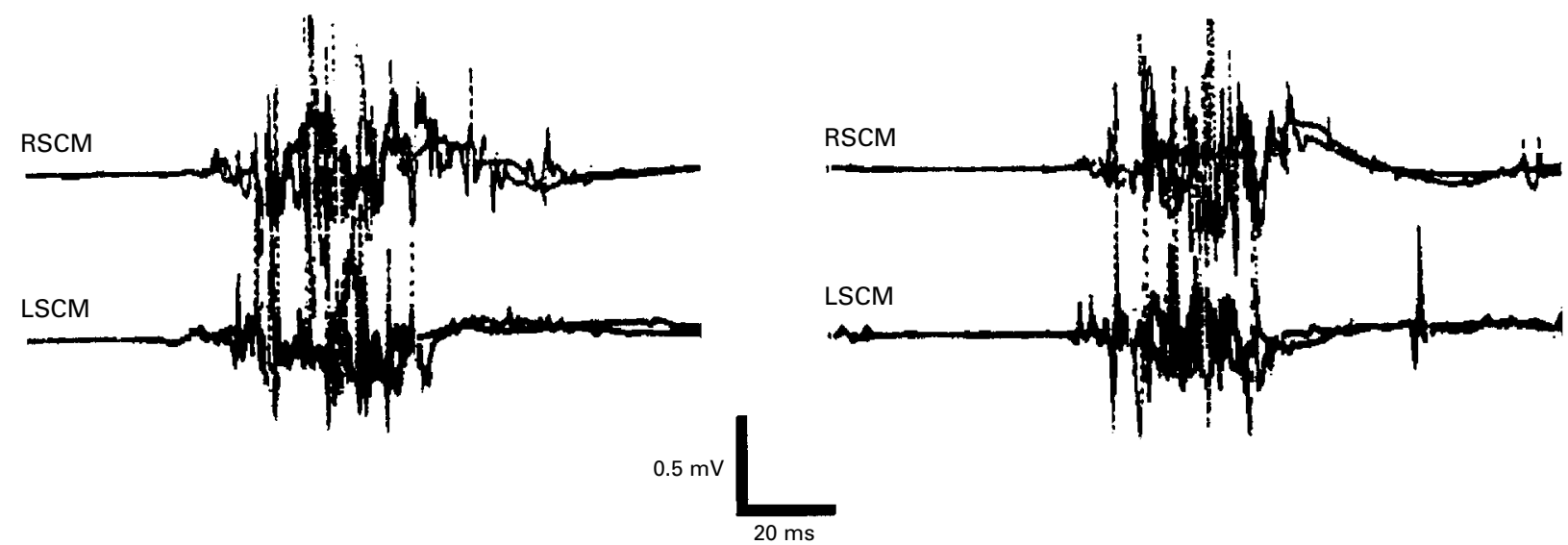

Figure 4 Control patient 12. Right Bell's facial palsy. Simultaneous recording in the sternocleidomastoideus (SCM) muscles by means of concentric needle electrodes. Supraorbital nerve stimulation provokes bilateral late reflex responses; the complete right facial palsy ruled out the possibility of a diffuse response from the platysma muscle in this side.

\section{Discussion}

The evoked responses that were obtained with the electrical stimulation of the supraorbital nerve in SCM muscles of the control group and in the reinnervated facial muscles of the pathological group must be considered reflex responses driven throughout a trigeminoaccessory pathway. This situation is only possible if a central connection exists between the afferent trigeminal limb and the spinal nuclei of the 11 th cranial nerve.

Experimental data exist that show activation of the motor neurons of the first cervical segments on trigeminal nerve stimulation. ${ }^{45}$ In humans, reflex responses have also been found in cervical muscles after stimulation of trigeminal branches. ${ }^{26-8}$ Sartucci et al found cervical responses recorded within the SCM and trapezius muscles in all 21 normal people tested with an electrical stimulation from each of the trigeminal branches. Responses were always bilateral, with a unique component in each side and their mean latency was 48.7 (SD 8.1) ms. They eventually proposed this reflex as a new method to evaluate lesions in the medulla and upper spinal cord segments. ${ }^{7}$ These data show important differences in the latency as well as the incidence of the responses in comparison with our own. The discrepancies might be partly accounted for by the different recording methods used; surface electrodes employed by these authors do not accurately permit the differentiation of the SCM activity from that of the overlying platysma colli muscle, a muscle supplied by the facial nerve which could be implicated in the normal trigeminofacial reflex response. In the current study, concentric needle electrodes have been used, which should decrease the possibility of volume conduction from other close muscular territories. Moreover, the presence of a response on the ipsilateral side to the lesion in the subgroup of patients with complete Bell's palsy (fig 4), rules out the possibility of diffusion from neighbouring facial muscles and confirms the accessory nerve as the efferent limb of the reflex.
A trigemino-accessory reflex response was found in $57 \%$ of the normal subjects; in the group of patients with accessory-facial anastomosis the incidence of responses was significantly higher and of more complex configuration, with frequent double component similar to the typical blink-reflex response. It is difficult to explain the high incidence of the R1 response in the accessory-facial anastomosis group as opposed to its only occasional presence in the control group. However, given that the plasticity mechanism could control a fine functional target, it could be accepted that a "two component" blink reflex response (six out of 11 in the series) would be more complete and perhaps more "functionally useful" than a "one component" response, whatever the reflex component obtained would be. A mechanism of synaptic plasticity should facilitate the reflex responses. After the abnormal conditions created by the surgical lesion of the accessory nerve, with the subsequent regeneration phenomena and reinnervation of new muscular territories, this pathway could reach a high degree of functional facilitation in relation to the basal state, due to a mechanism of induced neuronal plasticity. ${ }^{9-11}$ Plasticity of the nervous system could be due to an unmasking mechanism that turns on some synaptic connections, which were anatomically preformed but functionally inhibited; the inhibition could be mediated by GABA. ${ }^{12}$ This mechanism would begin when the dominant system is damaged. ${ }^{13}$ The existence of preformed pathways in the brainstem which remain inhibited in normal conditions has been considered in diseases which alter the excitability of the facial area and the appearance of an unusual contralateral R1 response in the trigeminofacial blink reflex has been described in these situations. ${ }^{14-16}$

Anatomically, connections between the nuclei of the Vth, VIIth, and XIIth cranial nerves through the lateral tegmental field have been demonstrated ${ }^{17}$; connections between the trigeminal and accesory nerves are less clearly proved but there are some data that support this relation. Cajal ${ }^{18}$ described a contingent of 
thin fibres coming from the descendent branches of the Vth cranial nerve and going to the area of origin of the spinal portion of the XIth cranial nerve. Other authors have described trigeminal fibres of the spinal tract which reach the posterior horn at the $\mathrm{C} 3^{4}{ }^{19} 20$ or C4 level. ${ }^{21}$ These fibres would probably establish some connections with the motor neurons of the accessory nerve.

Another exteroceptive reflex in SCM muscles after electrical stimulation of the supraorbital nerve has been described in normal subjects. $^{22}$ This reflex was induced in both SCM muscles during a voluntary contraction of moderate intensity. In these conditions unilateral supraorbital stimulation induced the suppression of the activity between two facilitation periods; the first one was short and inconstant (sometimes absent) and the second one, occurring immediately after the inhibition period, was longer and began around $70 \mathrm{~ms}$ after the stimulus. This distribution of responses, their configuration, and their incidence were similar to our results. The systematic existence of the responses in normal people could probably be due to the presence of a basal voluntary activity when the electrical stimuli are delivered; in this situation the facilitation of any reflex response has been seen. ${ }^{23}$ The inconsistency of the first period of facilitation, even in these conditions, is similar to the absence of the early response found in our normal group. This fact contrasts with the almost systematic obtention of an R1 response in the pathological group of patients with accessoryfacial anastomosis being probably the consequence of a "neurobionomic" process of facilitation. The neurobionomic function defines the mechanisms of an integrated sensorymotor activity that turn on after neuroanatomical lesions according to the demand of the external environment. ${ }^{3}$

In normal subjects the existence of reflex responses in muscles supplied by the hypoglossal nerve evoked by the trigeminal stimulation is not clearly established (we did not obtain them in the three subjects evaluated). Nevertheless, these responses have been described in a group of patients after a hypoglosal-facial anastomosis performed for the treatment of facial hemispasm and acoustic neuroma. ${ }^{24}$ The situation could be similar to that of the accessory nerve.

In conclusion, the lesion of the efferent limb of a preformed trigemino-accessory reflex probably facilitates the response by a mechanism of synaptic adaptative plasticity. The reason why the embryo possesses more path- ways than those which are going to be used in adults is unknown. A safety factor would tend to maintain them-although inhibitedinstead of abolishing them when their function during the adult period would have finished.

1 Sumino R, Nozaki S. Trigemino-neck reflex: its peripheral and central organization. In: Anderson DJ, Matthews B, eds. Pain in the trigeminal region. Amsterdam:

2 Sartucci F, Rossi A, Rossi B. Trigemino cervical reflex in man. Electromyogr Clin Neurophysiol 1986;26:123-9.

3 Melwill-Jones G, Mandl G. Neurobionomics of adaptative plasticity: integrating sensorymotor function with enviromental demands. In: Desmedt JE, ed. Motor control mechanism in health and disease. New York: Raven Press, 1983:1047-71.

4 Kerr FW, Olafson RA, Minn R. Trigeminal and cervical volleys. Arch Neurol 1961;5:171-8.

5 Manni E, Palmieri G, Marini R, et al. Trigeminal influences on extensor muscles of the neck. Exp Neurol 1975;47:330 42.

6 Goor C. Investigation of brainstem reflexes. In: Notermans SLH, ed. Current practice of clinical electromyography. Amsterdam: Elsevier, 1984:404.

7 Rossi B, Pasca SL, Sartucci F, et al. Trigemino-cervical reflex in pathology of the brain stem and of the first cervical cord segments. Electromyogr Clin Neurophysiol 1989;29: $67-71$.

8 Ertekin C, Celebisoy N, Uludag B. Trigemino-cervical reflexes in normal subjects. F Neurol Sci 1996;143:84-90.

9 Wall PD, Egger MD. Formation of new conexions in adult rat brains after parcial deafferentation. Nature 1971;232: $542-5$.

10 Devor M, Wall PD. Reorganisation of spinal cord sensory map after peripheral nerve injury. Nature 1978;276:75-6.

11 Willer JC, Lamas G, Fligny I, et al. Hypoglossal-facial anastomosis alters excitability of hypoglossal motoneurones in man. Neurosci Lett 1993;155:212-5.

12 Wall PD. Do nerve impulses penetrate terminal arborizations? A pre-presynaptic control mechanism. Trends in Neuroscience 1995;18:99-103.

13 Wall PD, Noordenbos W. Sensory functions which remain in man after complete transection of dorsal columns. Brain 1977; 100:641-53.

14 Nacimento W, Podoll K, Graeber MB, et al. Contralateral early blink reflex in patients with facial nerve palsy: indication for synaptic reorganization in facial nucleus during regeneration. F Neurol Sci 1992;109:148-55.

15 Klostermann W, Wessel K. Crossed R1 response of the blink reflex in peripheral facial palsy. Electromyogr Clin Neurophysiol 1995;35:69-71.

16 Leon-S F, Arimura K, Arimura Y, et al. Contralateral early blink-reflex in patients with HTLV-I associated myelopathy/tropical spastic paraparesis. F Neurol Sci 1995; 128:51-7.

17 Holstege G, Kuypers HGJM, Dekker JJ. The organization of the bulbar fibre connections to the trigeminal, facial and hypoglossal motor nuclei. An autoradiographic tracing study in cat. Brain 1977;100:265-86.

18 Cajal SR. Histologie du systeme nerveux de l'homme et des vertebrés. Madrid: Consejo Superior de Investigaciones Científicas, 1972:864.

19 Taren JA. The positions of the cutaneous components of the acial, glossopharyngeal and vagal nerves in the spinal tract of V. F Comp Neurol 1964;122:389-97.

20 Rhoton AL, O'Lehary JL, Ferguson JP. The trigeminal, facial and glosopharyngeal nerves in the monkey. Afferent connections. Arch Neurol 1966;14:530-40.

21 Torvik A. Afferent connections to the sensory trigeminal nuclei, the nucleus of solitary tract and adjacent structures. An experimental study in the rat. F Comp Neurol 1956;106: 142.

22 Nakashima K, Thompson PD, Rothwell JC, et al. An exteroceptive reflex in the sternocleidomastoid muscle produced by electrical stimulation of the supraorbital nerve in duced by electrical stimulation of the supraorbital nerve in normal subjects and patient

23 Lumberg A, Voorhoeve P. Effects of the pyramidal tract on spinal reflex arcs. Acta Physiol Scand 1962;56:201-19.

24 Iansek R, Harrison M, Andrew J. Hypoglossal-facial nerve anastomosis: a clinical and electrophysiological follow-up. $\mathcal{f}$ Neurol Neurosurg Psychiatry 1986;49:588-90. 